\title{
Diabetes and Driving
}

American Diabetes Association

0 f the nearly 19 million people in the U.S. with diagnosed diabetes (1), a large percentage will seek or currently hold a license to drive. For many, a driver's license is essential to work; taking care of family; securing access to public and private facilities, services, and institutions; interacting with friends; attending classes; and/or performing many other functions of daily life. Indeed, in many communities and areas of the U.S. the use of an automobile is the only (or the only feasible or affordable) means of transportation available.

There has been considerable debate whether, and the extent to which, diabetes may be a relevant factor in determining driver ability and eligibility for a license. This position statement addresses such issues in light of current scientific and medical evidence.

Sometimes people with a strong interest in road safety, including motor vehicle administrators, pedestrians, drivers, other road users, and employers, associate all diabetes with unsafe driving when in fact most people with diabetes safely operate motor vehicles without creating any meaningful risk of injury to themselves or others. When legitimate questions arise about the medical fitness of a person with diabetes to drive, an individual assessment of that person's diabetes management-with particular emphasis on demonstrated ability to detect and appropriately treat potential hypoglycemia-is necessary in order to determine any appropriate restrictions. The diagnosis of diabetes is not sufficient to make any judgments about individual driver capacity.

This document provides an overview of existing licensing rules for people with diabetes, addresses the factors that impact driving for this population, and identifies general guidelines for assessing driver fitness and determining appropriate licensing restrictions.

\section{LICENSING \\ REQUIREMENTS-People with dia-} betes are currently subject to a great variety of licensing requirements and restrictions. These licensing decisions occur at several points and involve different levels and types of review, depending on the type of driving. Some states and local jurisdictions impose no special requirements for people with diabetes. Other jurisdictions ask drivers with diabetes various questions about their condition, including their management regimen and whether they have experienced any diabetes-related problems that could affect their ability to safely operate a motor vehicle. In some instances, answers to these questions result in restrictions being placed on a person's license, including restrictions on the type of vehicle they may operate and/or where they may operate that vehicle. In addition, the rules for operating a commercial motor vehicle, and for obtaining related license endorsements (such as rules restricting operation of a school bus or transport of passengers or hazardous materials) are quite different and in many ways more cumbersome for people with diabetes, especially those who use insulin.

With the exception of commercial driving in interstate commerce (Interstate commercial driving is defined as trade, traffic or transportation in the United States between a place in a state and a place outside of such a state, between two places in a state through another state or a place outside of the United States, or between two places in a state as part of trade, traffic or transportation originating or terminating outside the state or the United States [2]), which is subject to uniform federal regulation, both private and commercial driving are subject to rules determined by individual states. These rules vary widely, with each state taking its own approach to determining medical fitness to drive and the issuance of licenses. How diabetes is

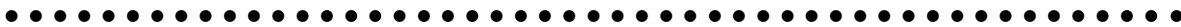

Peer reviewed by the Professional Practice Committee, September 2011, and approved by the Executive Committee of the American Diabetes Association, November 2011.

DOI: $10.2337 / \mathrm{dcl} 3-\mathrm{S} 080$

(C) 2013 by the American Diabetes Association. Readers may use this article as long as the work is properly cited, the use is educational and not for profit, and the work is not altered. See http://creativecommons.org/ licenses/by-nc-nd/3.0/ for details.
}

identified, which people are medically evaluated, and what restrictions are placed on people who have experienced hypoglycemia or other problems related to diabetes all vary from state to state.

States identify drivers with diabetes in a number of ways. In at least 23 states, drivers are either asked directly if they have diabetes or are otherwise required to self-identify if they have diabetes. In other states drivers are asked some variation of a question about whether they have a condition that is likely to cause altered perception or loss of consciousness while driving. In most states, when the answer to either question is yes, the driver is required to submit to a medical evaluation before he or she will be issued a license.

\section{Medical evaluation}

Drivers whose medical conditions can lead to significantly impaired consciousness are evaluated for their fitness to continue to drive. For people with diabetes, this typically occurs when a person has experienced hypoglycemia (3) behind the wheel, even if this did not result in a motor vehicle accident. In some states this occurs as a result of a policy to evaluate all people with diabetes, even if there has been no triggering event. It can also occur when a person experiences severe hypoglycemia while not driving and a physician reports the episode to the licensing authority. In a handful of states, such reporting by physicians is mandatory. In most other states physicians are permitted to make reports but are given discretion to determine when such reports are necessary. Some states specify that physicians may voluntarily report those patients who pose an imminent threat to public safety because they are driving against medical advice. Physicians and others required to make reports to the licensing authority are usually provided with immunity from civil and criminal actions resulting from the report.

When licensing authorities learn that a driver has experienced an episode of hypoglycemia that potentially affected the ability to drive, that driver is referred for a medical evaluation and in many cases will lose driving privileges for a period of time until cleared by the licensing authority. This period can range from 3 to 6 months or longer. Some state laws allow for waivers of the rules when the episode is a one-time event not likely to recur, for 
example because of a change in medication or episodes that occur only during sleep.

Medical evaluation procedures vary and range from a simple confirmation of the person's diabetes from a physician to a more elaborate process involving a state medical advisory board, hearings, and presentation and assessment of medical evidence. Some states convene medical advisory boards with nurses and physicians of different specialties who review and make recommendations concerning the licensing of people with diabetes and other medical conditions. In other states, licensing decisions are made by administrative staff with little or no medical training and with little or no review by a medical review board or by a physician or physicians with any relevant expertise concerning medical conditions presented by individual applicants.

The medical evaluation process for commercial drivers occurs at predetermined intervals, typically every 2 years. Unlike noncommercial licenses, these regular evaluations are not linked to episodes of severe hypoglycemia but are part of an ongoing fitness evaluation for jobs requiring commercial driving. The federal government has no diabetes-specific restrictions for individuals who manage their disease with diet, exercise, and/or oral medication. It offers an exemption program for insulin-using interstate commercial drivers and issues medical certificates to qualified drivers. Factors in the federal commercial driving medical evaluation include a review of diabetes history, medications, hospitalizations, blood glucose history, and tests for various complications and an assessment of driver understanding of diabetes and willingness to monitor their condition.

\section{SCIENCE OF DIABETES AND}

DRIVING-Hypoglycemia indicating an impaired ability to drive, retinopathy or cataract formation impairing the vision needed to operate a motor vehicle, and neuropathy affecting the ability to feel foot pedals can each impact driving safety (4). However, the incidence of these conditions is not sufficiently extensive to justify restriction of driving privileges for all drivers with diabetes. Driving mishaps related to diabetes are relatively infrequent for most drivers with diabetes and occur at a lower rate than mishaps of many other drivers with conditions that affect driving performance and that are tolerated by society.

However, just as there are some patients with conditions that increase their risk of incurring driving mishaps, such as unstable coronary heart disease, obstructive sleep apnea, epilepsy, Parkinson's disease, or alcohol and substance abuse, there are also some drivers with diabetes that have a higher risk for driving mishaps. The challenges are to identify highrisk individuals and develop measures to assist them to lower their risk for driving mishaps.

\section{Understanding the risk of diabetes and driving}

In a recent Scottish study, only $62 \%$ of health care professionals suggested that insulin-treated drivers should test their blood glucose before driving; $13 \%$ of health care professionals thought it safe to drive with blood glucose $<72 \mathrm{mg} / \mathrm{dL}$ ( $4 \mathrm{mmol} / \mathrm{L})$, and $8 \%$ did not know that impaired awareness of hypoglycemia might be a contraindication to driving (5). It is important that health care professionals be knowledgeable and take the lead in discussing risk reduction for their patients at risk for hypoglycemia. In a large international study, nearly half of drivers with type 1 diabetes and three-quarters of those with type 2 diabetes had never discussed driving guidelines with their physician (8).

A meta-analysis of 15 studies suggested that the relative risk of having a motor vehicle accident for people with diabetes as a whole, i.e., without differentiating those with a significant risk from those with little or no risk, as compared with the general population ranges between 1.126 and 1.19 , a 12-19\% increased risk (6). Some published studies indicated that drivers with type 1 diabetes have a slightly higher risk, with a relative risk ratio of $\sim 2(7,8,9)$, but this was not confirmed by other studies (10). Two studies even suggested that there is no increased risk associated with insulin-treated diabetes $(11,12)$, but the methodologies used have been criticized (13).

This increased risk of collisions must be interpreted in the light of society's tolerance of other and much higher-risk conditions. For example, 16-year-old males have 42 times more collisions than 35- to 45-year-old women. If the heaviest car collides with the lightest car, the driver of the latter is 20 times more likely to be killed than the driver of the former. The most dangerous rural highways are 9.2 times more dangerous than the safest urban highways. Driving at 1:00 A.M. on Sunday is 142 times more dangerous than driving at 11:00 A.M. (7). Drivers with attention deficit/ hyperactivity disorder have a relative risk ratio of $\sim 4$ (14), whereas those with sleep apnea have a relative risk of $\sim 2.4$ (15). If society tolerates these conditions, it would be unjustified to restrict the driving privileges of an entire class of individuals who are at much lower risk, such as drivers with diabetes.

The most significant subgroup of persons with diabetes for whom a greater degree of restrictions is often applied is drivers managing their diabetes with insulin. Yet, when the type of diabetes is controlled for, insulin therapy per se has not been found to be associated with increased driving risk $(3,16,17)$. While impaired awareness of hypoglycemia has been found to relate to increased incidence of motor vehicle crashes in some studies (12), it has not been found to be a relevant variable in other studies $(4,7,23)$. The single most significant factor associated with driving collisions for drivers with diabetes appears to be a recent history of severe hypoglycemia, regardless of the type of diabetes or the treatment used $(1,3,18-21)$.

The American Diabetes Association Workgroup on Hypoglycemia defined severe hypoglycemia as low blood glucose resulting in neuroglycopenia that disrupts cognitive motor function and requires the assistance of another to actively administer carbohydrate, glucagon, or other resuscitative actions (22). In a prospective multicenter study of 452 drivers with type 1 diabetes followed monthly for 12 months, 185 participants (41\%) reported a total of 503 episodes of moderate hypoglycemia (where the driver could still treat him/herself but could no longer drive safely) and 23 participants (5\%) reported 31 episodes of severe hypoglycemia (where the driver was unable to treat him/herself) while driving (21). Conversely, the Diabetes Control and Complications Trial (DCCT) group reported 11 motor vehicle accidents in 714 episodes of severe hypoglycemia, a rate of $1.5 \%$ (23).

The significant impact of moderate hypoglycemia while driving is supported by multiple studies demonstrating that moderate hypoglycemia significantly and consistently impairs driving safety (24-26) and judgment $(27,28)$ as to whether to continue to drive or to self-treat $(29,30)$ under such metabolic conditions. In one study, $25 \%$ of respondents thought it was safe to drive even when blood glucose was $<70$ $\mathrm{mg} / \mathrm{dL}$ (3.9 mmol/L) (31).

While significant hyperglycemia may impair cognitive, motor, and perceptual functioning (32-35), there is only one report suggesting extreme hyperglycemia can impact driving safety (36). Thus, 
efforts to equate hyperglycemia with driving impairment are currently not scientifically justified.

\section{Individual differences}

Eighty percent of episodes of severe hypoglycemia affect about 20\% of people with type 1 diabetes (37-39). Available data suggest that a small subgroup of drivers with type 1 diabetes account for the majority of hypoglycemia-related collisions $(9,30,40)$. When 452 drivers with type 1 diabetes were followed prospectively for a year, baseline reports of prior episodes of mild symptomatic hypoglycemia while driving or severe hypoglycemia while driving, hypoglycemia-related driving mishaps, or hypoglycemia-related collisions were associated with a higher risk of driving mishaps in the following 12 months by 3, 6, 6, and $20 \%$, respectively. Risk increased exponentially with additional reported episodes: If individuals had two episodes of severe hypoglycemia in the preceding 12 months their risk increased to $12 \%$, and two collisions in the previous 2 years increased their risk by $40 \%$. The strongest predictors involved a history of hypoglycemia while driving (21). Laboratory studies that compared drivers with type 1 diabetes who had no history of hypoglycemia-related driving mishap in the past year to those who had more than one mishap found that those with a history of mishaps: 1) drove significantly worse during progressive mild hypoglycemia $(70-50 \mathrm{mg} / \mathrm{dL}$, 3.9-2.8 mmol/L) but drove equally well when blood glucose was normal (euglycemia); 2) had a lower epinephrine response while driving during hypoglycemia, 3) were more insulin sensitive, and 4) demonstrated greater difficulties with working memory and information processing speed during euglycemia and hypoglycemia $(24,40,41)$. Thus, a history of mishaps should be used as a basis for identifying insulin-managed drivers with elevated risk of future mishaps. Such individuals are appropriately subjected to additional screening requirements.

Four studies have demonstrated that Blood Glucose Awareness Training (BGAT) reduces the occurrence of collisions and moving vehicle violations while improving judgment about whether to drive while hypoglycemic (42-45). BGAT is an 8-week psycho-educational training program designed to assist individuals with type 1 diabetes to better anticipate, prevent, recognize, and treat extreme blood glucose events. This intervention can be effectively delivered over the internet (46). Diabetes Driving (diabetesdriving.com), a program funded by the National Institutes of Health, is another internet-based tool to help assess the risk of driving mishaps and assist highrisk drivers to avoid hypoglycemia while driving and to better detect and manage hypoglycemia if it occurs while driving.

\section{RECOMMENDATIONS}

\section{Identifying and evaluating diabetes in drivers}

Individuals whose diabetes poses a significantly elevated risk to safe driving must be identified and evaluated prior to getting behind the wheel. Because people with diabetes are diverse in terms of the nature of their condition, the symptoms they experience, and the measures they take to manage their diabetes, it is important that identification and evaluation processes be appropriate, individualized, and based not solely on a diagnosis of diabetes but rather on concrete evidence of actual risk. Laws that require all people with diabetes (or all people with insulin-treated diabetes) to be medically evaluated as a condition of licensure are ill advised because they combine people with diabetes into one group rather than identifying those drivers who may be at increased risk due to potential difficulties in avoiding hypoglycemia or the presence of complications. In addition, the logistics of registering and evaluating millions of people with diabetes who wish to drive presents an enormous administrative and fiscal burden to licensing agencies. States that require drivers to identify diabetes should limit the identification to reports of diabetesrelated problems.

To identify potentially at-risk drivers, a short questionnaire can be used to find those drivers who may require further evaluation. The questionnaire should ask whether the driver has, within the past 12 months, lost consciousness due to hypoglycemia, experienced hypoglycemia that required intervention from another person to treat or that interfered with driving, or experienced hypoglycemia that developed without warning. The questionnaire should also query about loss of visual acuity or peripheral vision and loss of feeling in the right foot. Inasmuch as obstructive sleep apnea is more common in people with type 2 diabetes than in the nondiabetic population, patients should be queried about falling asleep during the day. Any positive answer should trigger an evaluation to determine whether restrictions on the license or mechanical modifications to the vehicle (e.g., hand controls for people with an insensate foot) are necessary to ensure public safety. It is ill-advised to determine risk for driving mishaps based on a driver's glycosylated hemoglobin because episodic transitions into hypoglycemia, not average blood glucose, increases risk of driving mishaps.

Evaluation of drivers with diabetes must include an assessment by the treating physician or another diabetes specialist who can review recent diabetes history and provide to the licensing agency a recommendation about whether the driver has a condition that impairs his or her ability to safely operate a motor vehicle. The treating physician or another physician who is knowledgeable about diabetes is the best source of information concerning the driver's diabetes management and history. The input of such a physician is essential to assess a person's diabetes management and determine whether operation of a motor vehicle is safe and practicable. If questions arise concerning the safe driving ability of a person with chronic complications of diabetes (e.g., retinopathy or neuropathy), the individual should be referred to a specialist with expertise in evaluating the diabetes-related problem for specific recommendations.

Physicians should be requested to provide the following information: 1) whether the driver has had an episode of severe hypoglycemia requiring intervention from another person within the previous 2 years (and when this happened); 2) whether there was an explanation for the hypoglycemia; 3) whether the driver is at increased risk of severe hypoglycemia; 4) whether the driver has the ability to recognize incipient hypoglycemia and knows how to take appropriate corrective action; 5) whether the driver provides evidence of sufficient self-monitoring of blood glucose; 6) whether the driver has any diabetes-related complications affecting safe driving that need further assessment; and 7) whether the driver has a good understanding of diabetes and its treatment, has been educated on the avoidance of hypoglycemia while driving, and is willing to follow a suggested treatment plan.

When evaluating a driver with a history of severe hypoglycemia, impaired hypoglycemia awareness, or a diabetes-related motor vehicle accident, it is necessary to 
investigate the reasons for the hypoglycemia and to determine whether it is a function of the driver's treatment regimen or lifestyle, a psychological reaction to the management of their diabetes, or the normal course of diabetes. Appropriate clinical interventions should be instituted.

\section{Licensing decisions following evaluation}

Drivers with diabetes should only have a license suspended or restricted if doing so is the only practical way to address an established safety risk. Licensing decisions should reflect deference to the professional judgment of the evaluating physician with regard to diabetes, while also balancing the licensing agency's need to keep the roads and the public safe. States should have medical advisory boards whose role is to assess potential driving risks based on continually updated medical information, to ensure that licensing agency staff is prepared to handle diabetes licensing issues, and to make recommendations relevant to individual drivers. State medical advisory boards should have representation by health care professionals with expertise in treating diabetes, in addition to the information provided by the driver's treating physician, prior to making licensing decisions for people with diabetes. Where the medical advisory board does not have a permanent member with expertise in diabetes, such an expert should be consulted in cases involving restrictions on a driver with diabetes.

As discussed above, a history of hypoglycemia does not mean an individual cannot be a safe driver. Rather, when there is evidence of a history of severe hypoglycemia, an appropriate evaluation should be undertaken to determine the cause of the low blood glucose, the circumstances of the episode, whether it was an isolated incident, whether adjustment to the insulin regimen may mitigate the risk, and the likelihood of such an episode recurring. It is important that licensing decisions take into consideration contributory factors that may mitigate a potential risk, and that licensing agencies do not adopt a "one strike" approach to licensing people with diabetes. Drivers with diabetes must be individually assessed to determine whether their diabetes poses a safety risk. The mere fact that a person's diabetes has come to the attention of the licensing agency-whether by a report or because of an accident-should not itself predetermine a licensing decision.
Generally, severe hypoglycemia that occurs during sleep should not disqualify a person from driving. Hypoglycemia that occurs while the person is not driving should be examined to determine if it is indicative of a larger problem or an event that is not likely to recur while the person is behind the wheel of a car (e.g., hypoglycemia that occurs during an intense bout of exercise). Some episodes of severe hypoglycemia can be explained and corrected with the assistance of a diabetes health care professional, e.g., episodes that occur because of a change in medication. However, recurrent episodes of severe hypoglycemia, defined as two or more episodes in a year, may indicate that a person is not able to safely operate a motor vehicle.

States whose licensing rules lead to a suspension of a driver's license following an episode of hypoglycemia should allow for waiver of these rules when the hypoglycemia can be explained and addressed by the treating physician and is not likely to recur. For example, waivers may be appropriate following hypoglycemia that happens as a result of a change in medication or during or concurrent with illness or pregnancy. Licensing agencies may request documentation from the physician attesting that the patient meets the conditions for a waiver (which may include, among other requirements, education on diabetes management and avoidance of hypoglycemia).

Drivers with a suspended license because of factors related to diabetes should be eligible to have their driver's license reinstated following a sufficient period of time (usually no more than 6 months) upon advice from the treating physician that the driver has made appropriate adjustments and is adhering to a regimen that has resulted in correction of the problems that led to the license suspension. Following reinstatement of driving privileges, periodic follow-up evaluation is necessary to ensure that the person remains safely able to operate a motor vehicle.

People who experience progressive impairment of their awareness of hypoglycemia should consult a health care provider to determine whether it is safe to continue driving with proper measures to avoid disruptive hypoglycemia (such as testing blood glucose before driving and at regular intervals in the course of a journey lasting more than 30-60 min). If the driver is able to make adjustments to improve awareness or prevent disruptive hypoglycemia while driving, there should not be license restrictions. Continuous glucose monitoring may also be beneficial, particularly when noting the direction of the glucose trend. If this technology is used, the person using the device needs to appreciate that any action taken (e.g., additional carbohydrate consumption) needs to be based on a blood glucose measurement.

The determination of which disqualified drivers should be reevaluated and when this should be done should be made on an individual basis considering factors such as the circumstances of the disqualifying event and changes in medication and behavior that have been implemented by the driver. When an assessment determines that the driver should be evaluated at some point in the future, the driver's physician should be consulted to determine the length of the reevaluation period. A driver with diabetes should not be kept in an endless cycle of reevaluation if there is no longer a significantly elevated safety risk.

The determination of medical fitness to drive should be a clinical one, weighing the various factors noted above. Decisions about whether licensing restrictions are necessary to ensure safety of the traveling public are ultimately determined by the licensing agency, taking into account the clinical determination of medical fitness.

\section{Physician reporting}

Although the concept behind mandatory physician reporting laws is to keep roads safe by eliminating unacceptable risk from impaired driving, such laws have the unintended consequence of discouraging people with diabetes from discussing their condition frankly with a physician when there is a problem that needs correction due to fear of losing their license. Patients who are not candid with their physicians are likely to receive inferior treatment and therefore may experience complications that present a driving risk. In addition to the negative effect that mandatory reporting has on the physician-patient relationship, there is no evidence that mandatory physician reporting reduces the crash rate or improves public safety (47).

Physicians should be permitted to exercise professional judgment in deciding whether and when to report a patient to the licensing agency for review of driving privileges. States that allow physicians to make such reports should focus on whether the driver's mental or physical condition impairs the patient's ability to exercise safe control over a motor vehicle. 
Reports based solely on a diagnosis of diabetes, or tied to a characterization that the driver has a condition involving lapses of consciousness, are too broad and do not adequately measure individual risk. Ultimately, reports must be left to the discretion of the physician, using professional judgment about whether the patient poses a safety risk. Further, in order to protect the physician-patient relationship and ensure the open and honest communication that ultimately promotes safety, it is important that physicians be immunized from liability, both for making reports and not making reports.

\section{Patient education and clinical interventions}

It is important that health care professionals be knowledgeable and take the lead in discussing risk reduction for their patients at risk for disruptive hypoglycemia. This starts with health care professionals being conversant with safe practices, particularly for those patients at increased risk for diabetes-related incidents. Perhaps the most important aspect of encouraging people with diabetes to be safe drivers is for health care professionals who treat diabetic drivers to provide education about driving with diabetes and potential risks associated with patients' treatment regimens. When that regimen includes the possibility of hypoglycemia, education should include instruction on avoiding and responding to hypoglycemia, discussion about the patient's vulnerability for driving mishaps, and ongoing learning to ensure that patients have knowledge of when it is and is not safe for them to drive. For example, the risks of driving under the influence of alcohol are well known, but the delayed hypoglycemic effects of even moderate alcohol intake are not, and alcohol exacerbates the cognitive impairment associated with hypoglycemia (48). Inasmuch as hypoglycemia can be mistaken for intoxication, and both increase the risk of motor vehicle accidents, patients should be counseled to test glucose more frequently for several hours after moderate alcohol intake. When a patient has complications of diabetes, it is important for the physician to discuss with the driver the effect of those complications, if any, on driving ability.

Physicians and other health care professionals who treat people with diabetes should regularly discuss the risk of driving with low blood glucose with their patients. Clinical visits should include review of blood glucose logs and questions to the patient about symptoms associated with high or low blood glucose levels and what the patient did to treat those levels. Allowing health care professionals to exercise professional judgment about the information they learn in these patient conversations will encourage candid sharing of information and lead to improved patient health and road safety.

Clinical interventions in response to hypoglycemia vary by individual but may include strategies for the frequency and timing of blood glucose monitoring, medication dosage changes, and establishing more conservative glucose targets if there is a history of severe hypoglycemia. Certain people who have a history of severe hypoglycemia may be encouraged by their health care provider to use continuous glucose monitoring systems that enable them to detect a trend toward hypoglycemia before glucose levels fall to a level that will affect safe driving.

Of note, special care should be taken to prevent hypoglycemia while operating any vehicle in drivers with type 1 diabetes and in those with type 2 diabetes who are at risk for developing hypoglycemia. They should be instructed to always check blood glucose before getting behind the wheel and at regular intervals while driving for periods of $1 \mathrm{~h}$ or greater. Consideration should be given to factors that may predict a fall in blood glucose, including time of insulin administration, timing of the last meal or food ingestion, and exercise type, duration, intensity, and timing. Low blood glucose values should be treated immediately and appropriately, and the driver should not drive until blood glucose is in a safely acceptable range, usually after 30-60 min because of delayed recovery of cognitive function.

People with diabetes who are at risk for disruptive hypoglycemia should be counseled to: 1) always carry a blood glucose meter and appropriate snacks, including a quick-acting source of sugar (such as juice, nondiet soda, hard candy, or dextrose tablets) as well as snacks with complex carbohydrate, fat, and protein (e.g., cheese crackers), in their vehicle; 2) never begin an extended drive with low normal blood glucose (e.g., 70-90 $\mathrm{mg} / \mathrm{dL}$ ) without prophylactic carbohydrate consumption to avoid a fall in blood glucose during the drive; 3) stop the vehicle as soon any of the symptoms of low blood glucose are experienced and measure and treat the blood glucose level; and 4) not resume driving until their blood glucose and cognition have recovered.
CONCLUSION-In summary, people with diabetes should be assessed individually, taking into account each individual's medical history as well as the potential related risks associated with driving.

Acknowledgments-The American Diabetes Association thanks the members of the writing group for developing this statement: Daniel Lorber, MD, FACP, CDE (Chair); John Anderson, MD; Shereen Arent, JD; Daniel J. Cox, PhD, ABPP; Brian M. Frier, BSc, MD, FRCPE, FRCPG; Michael A. Greene, JD; John W. Griffin, Jr., JD; Gary Gross, JD; Katie Hathaway, JD; Irl Hirsch, MD; Daniel B. Kohrman, JD; David G. Marrero, PhD; Thomas J. Songer, PhD; and Alan L. Yatvin, JD.

\section{References}

1. Centers for Disease Control and Prevention. National Diabetes Fact Sheet: $\mathrm{Na}$ tional Estimates and General Information on Diabetes and Prediabetes in the U.S., 2011 Atlanta, GA, U.S. Department of Health and Human Services, Centers for Disease Control and Prevention, 2011

2. Code of Federal Regulation. Title 49: Transportation. Subpart A: General Applicability and Definitions. $\S 390.5$

3. American Diabetes Association. Standards of medical care in diabetes-2013 (Position Statement). Diabetes Care 2013;36 (Suppl. 1):S11-S66

4. Cox DJ, Kovatchev BK, Vandecar K, Gonder-Frederick L, Ritterband L, Clarke W. Hypoglycemia preceding fatal car collisions. Diabetes Care 2006;29:467-468

5. Watson WA, Currie T, Lemon JS, Gold AE. Driving and insulin-treated diabetes: who knows the rules and recommendations? Pract Diabetes Int 2004;24:201-206

6. ECRI. Diabetes and Commercial Motor Vehicle Safety (Federal Motor Carrier Safety Administration). June 2011 Update. Plymouth Meeting, Pennsylvania, ECRI, 2011

7. Lave LB, Songer TJ, LaPorte RE. Should persons with diabetes be licensed to drive trucks? Risk management. Risk Anal 1993;13:327-334

8. Harsch IA, Stocker S, Radespiel-Tröger $\mathrm{M}$, et al. Traffic hypoglycaemias and accidents in patients with diabetes mellitus treated with different antidiabetic regimens. J Intern Med 2002;252:352-360

9. Cox DJ, Penberthy JK, Zrebiec J, et al. Diabetes and driving mishaps: frequency and correlations from a multinational survey. Diabetes Care 2003;26:2329-2334

10. Stork ADM, van Haeften TW, Veneman TF. Diabetes and driving: desired data, research methods and their pitfalls, current knowledge, and future research. Diabetes Care 2006;29:1942-1949

11. Lonnen KF, Powell RJ, Taylor D, Shore AC, MacLeod KM. Road traffic accidents and 
diabetes: insulin use does not determine risk. Diabet Med 2008;25:578-584

12. Eadington DW, Frier BM. Type 1 diabetes and driving experience: an eight-year cohort study. Diabet Med 1989;6:137-141

13. Major HG, Rees SDR, Frier BM. Driving and diabetes: DVLA response to Lonnen et al. Diabet Med 2009;26:191

14. Jerome L, Habinski L, Segal A. Attentiondeficit/hyperactivity disorder (ADHD) and driving risk: a review of the literature and a methodological critique. Curr Psychiatry Rep 2006;8:416-426

15. Tregear S, Reston J, Schoelles K, Phillips B. Obstructive sleep apnea and risk of motor vehicle crash: systematic review and meta-analysis. J Clin Sleep Med 2009; 5:573-581

16. Laberge-Nadeau C, Dionne G, Ekoé JM, et al. Impact of diabetes on crash risks of truck-permit holders and commercial drivers. Diabetes Care 2000;23:612-617

17. Tregear SJ, Rizzo M, Tiller M, et al. Diabetes and motor vehicle crashes: a systematic evidence-based review and meta-analysis. In Proceedings of the Fourth International Driving Symposium on Human Factors in Driver Assessment, Training and Vehicle Design. Iowa City, Iowa, The University of Iowa, 2007, p. 343-350

18. Songer TJ. Low blood sugar and motor vehicle crashes in persons with type 1 diabetes. Annu Proc Assoc Adv Automot Med 2002;46:424-427

19. Songer TJ, Dorsey RR. High risk characteristics for motor vehicle crashes in persons with diabetes by age. Annu Proc Assoc Adv Automot Med 2006;50:335-351

20. Redelmeier DA, Kenshole AB, Ray JG. Motor vehicle crashes in diabetic patients with tight glycemic control: a populationbased case control analysis. PLoS Med 2009;6:e1000192

21. Cox DJ, Ford D, Gonder-Frederick LG, et al. Driving mishaps among individuals with type 1 diabetes: a prospective study. Diabetes Care 2009;32:2177-2180

22. American Diabetes Association. Defining and reporting hypoglycemia in diabetes: a report from the American Diabetes Association Workgroup on Hypoglycemia. Diabetes Care 2005;28:1245-1249

23. The DCCT Research Group. Epidemiology of severe hypoglycemia in the diabetes control and complications trial. Am J Med 1991;90:450-459

24. Cox DJ, Gonder-Frederick LA, Clarke WL. Driving decrements in type I diabetes during moderate hypoglycemia. Diabetes 1993;42:239-243

25. Quillian WC, Cox DJ, Gonder-Frederick LA, Driesen NR, Clarke WL. Reliability of driving performance during moderate hypoglycemia in adults with IDDM. Diabetes Care 1994;17:1367-1368

26. Cox DJ, Gonder-Frederick LA, Kovatchev BP, Julian DM, Clarke WL. Progressive hypoglycemia's impact on driving simulation performance: occurrence, awareness and correction. Diabetes Care 2000;23: $163-170$

27. Weinger K, Kinsley BT, Levy CJ, et al. The perception of safe driving ability during hypoglycemia in patients with type 1 diabetes mellitus. Am J Med 1999;107:246-253

28. Clarke WL, Cox DJ, Gonder-Frederick LA, Kovatchev BP. Hypoglycemia and the decision to drive a motor vehicle by persons with diabetes. JAMA 1999;282:750754

29. Cox DJ, Gonder-Frederick LA, Kovatchev BP, Clarke WL. Self-treatment of hypoglycemia while driving. Diabetes Res Clin Pract 2001;54:17-26

30. Cox DJ, Kovatchev BP, Anderson SM, Clarke WL, Gonder-Frederick LA. Type 1 diabetic drivers with and without a history of recurrent hypoglycemia-related driving mishaps: physiological and performance differences during euglycemia and the induction of hypoglycemia. Diabetes Care 2010;33:2430-2435

31. Graveling AJ, Warren RE, Frier BM. Hypoglycaemia and driving in people with insulin-treated diabetes: adherence to recommendations for avoidance. Diabet Med 2004;21:1014-1019

32. Kovatchev BP, Cox DJ, Summers KH, Gonder-Frederick LA, Clarke WL. Postprandial glucose dynamics and associated symptoms in type 2 diabetes mellitus. J Appl Res 2003;3:449-458

33. Sommerfield AJ, Deary IJ, Frier BM. Acute hyperglycemia alters mood state and impairs cognitive performance in people with type 2 diabetes. Diabetes Care 2004; 27:2335-2340

34. Cox DJ, McCall A, Kovatchev BP, Sarwat S, Ilag LL, Tan MH. Effects of blood glucose rate of changes on perceived mood and cognitive symptoms in insulin-treated type 2 diabetes. Diabetes Care 2007;30: 2001-2002

35. Gonder-Frederick LA, Zrebiec JF, Bauchowitz AU, et al. Cognitive function is disrupted by both hypo- and hyperglycemia in school-aged children with type 1 diabetes: a field study. Diabetes Care 2009;32:1001-1006

36. Cox D, Ford D, Ritterband L, Singh H, Gonder-Frederick L. Disruptive effects of hyperglycemia on driving in adults with type 1 and 2 diabetes (Abstract). Diabetes 2011;60(Suppl. 1):A223
37. Pedersen-Bjergaard U, Pramming S, Heller SR, et al. Severe hypoglycaemia in 1076 adult patients with type 1 diabetes: influence of risk markers and selection. Diabetes Metab Res Rev 2004;20:479_ 486

38. Bognetti F, Brunelli A, Meschi F, Viscardi M, Bonfanti R, Chiumello G. Frequency and correlates of severe hypoglycaemia in children and adolescents with diabetes mellitus. Eur J Pediatr 1997;156:589-591

39. Rewers A, Chase HP, Mackenzie T, et al. Predictors of acute complications in children with type 1 diabetes. JAMA 2002; 287:2511-2518

40. Campbell LK, Gonder-Frederick LA, Broshek DK, et al. Neurocognitive differences between drivers with type 1 diabetes with and without a recent history of recurrent driving mishaps. Int J Diabetes Mellit 2010;2:73-77

41. Cox DJ, Kovatchev BP, Gonder-Frederick LA, Clarke WL. Physiological and performance differences between drivers with Type 1 Diabetes Mellitus (T1DM) with and without a recent history of driving mishaps: An exploratory study. Can J Diabetes 2003; 27:23-29

42. Cox DJ, Gonder-Frederick LA, Julian DM, Clarke W. Long-term follow-up evaluation of blood glucose awareness training. Diabetes Care 1994;17:1-5

43. Cox DJ, Gonder-Frederick LA, Polonsky W, Schlundt D, Julian D, Clarke W. A multicenter evaluation of blood glucose awareness training-II. Diabetes Care 1995; 18:523-528

44. Cox DJ, Gonder-Frederick LA, Polonsky W, Schlundt D, Kovatchev B, Clarke W. Blood glucose awareness training (BGAT2): long-term benefits. Diabetes Care 2001;24:637-642

45. Broers S, le Cessie S, van Vliet KP, Spinhoven P, van der Ven NC, Radder JK. Blood glucose awareness training in Dutch Type 1 diabetes patients. Shortterm evaluation of individual and group training. Diabet Med 2002;19:157-161

46. Cox DJ, Ritterband L, Magee J, Clarke W, Gonder-Frederick L. Blood glucose awareness training delivered over the Internet. Diabetes Care 2008;31:1527-1528

47. McLachlan RS, Starreveld E, Lee MA. Impact of mandatory physician reporting on accident risk in epilepsy. Epilepsia 2007:48:1500-1505

48. Cheyne EH, Sherwin RS, Lunt MJ, Cavan DA, Thomas PW, Kerr D. Influence of alcohol on cognitive performance during mild hypoglycaemia: implications for Type 1 diabetes. Diabet Med 2004;21: 230-237 